\title{
Overdiagnosis: one concept, three perspectives, and a model
}

Bjørn Hofmann, PhD ${ }^{1,2}$, Lynette Reid, $\mathrm{PhD}^{3}$, Stacy Carter, $\mathrm{PhD}^{4}$, Wendy Rogers, MD, PhD 5

1. Department in Health Sciences, Faculty of Medicine and Health Sciences, the Norwegian University of Science and Technology in Gjøvik, Norway, bjoern.hofmann@ntnu.no

2. Centre of Medical Ethics, Faculty of Medicine, the University of Oslo, Norway, b.m.hofmann@medisin.uio.no

3. Department of Bioethics, Faculty of Medicine, University of Dalhousie, Halifax, Canada, Lynette.Reid@Dal.Ca

4. Australian Centre for Health Engagement, Evidence and Values, School of Health and Society, University of Wollongong, Wollongong, NSW 2522, Australia, stacyc@uow.edu.au

5. Department of Philosophy and Department of Clinical Medicine, Macquarie University, Sydney, New South Wales, Australia, wendy.rogers@mq.edu.au

Abstract:

Defining, estimating, communicating about, and dealing with overdiagnosis is challenging. One reason for this is because overdiagnosis is a complex phenomenon. In this article we try to show that the complexity can be analysed and addressed in terms of three perspectives, i.e., that of the person, the professional, and the population. Individuals are informed about overdiagnosis based on population-based estimates. These estimates depend on professionals' conceptions and models of disease and diagnostic criteria. These conceptions in turn depend on individuals' experience of suffering, and on population level outcomes from diagnostics and treatment. As the personal, professional, and populational perspectives are not easily to reconcile, we must address them explicitly and facilitate interaction. Population-based estimates of overdiagnosis must be more directly informed by personal need for information. So must disease definitions and diagnostic criteria. Only then can individuals be appropriately informed about overdiagnosis.

Key words: overdiagnosis, disease, epidemiology, diagnosis, criteria 


\section{Overdiagnosis: one concept, three perspectives, and a model}

\section{Background}

In spite of considerable attention and extensive efforts, overdiagnosis remains difficult to define, demanding to measure, and hard to handle. There are many definitions and little agreement on their applicability, leading to vigorous debates on the extent of overdiagnosis. This makes it difficult to inform, discuss, and deliberate about overdiagnosis. In this paper we argue that understanding three key perspectives that underpin and complicate the concept of overdiagnosis is central to dealing with this crucial challenge for modern health care.

\section{Disagreements on overdiagnosis}

There are several points of disagreement about overdiagnosis. First, there is a debate on whether overdiagnosis hinges on the definition of other concepts such as diagnosis, disease, or wellbeing (14). Second, there is controversy over how to distinguish overdiagnosis from other related concepts, like medicalization (5-7). Third, while there is agreement that overdiagnosis is an evaluative or valueladen concept, there is disagreement regarding the kinds of evaluations involved in its definition, e.g., which harms (and benefits) to include $(8,9)$. Fourth, there are disputes as to whether competing mortality should be included in overdiagnosis and whether symptomatic as well as asymptomatic persons can be overdiagnosed. Fifth, there are controversies over what types of overdiagnosis exist $(8,10-12)$ or a unifying definition of overdiagnosis is possible. Sixth, there are disputes over how to measure overdiagnosis (13-16). Moreover, there is disagreement about the extent to which overdiagnosis stems from biological characteristics of disease, from features of the healthcare system, from industry influence, or from a broader social setting $(5,17)$. While a wide range of drivers have been identified (18), there is little consensus on which factors to address and how (19, 20). Table 1 summarises the main points of disagreement concerning the concept of overdiagnosis.

Table 1 Challenges and topics of disagreement regarding the concept of overdiagnosis

\begin{tabular}{ll}
\hline Challenge & Explanation / Example \\
\hline $\begin{array}{l}\text { Conceptual issues of } \\
\text { disease and diagnosis }\end{array}$ & $\begin{array}{l}\text { How does overdiagnosis relate to other concepts such as diagnosis, } \\
\text { disease, and wellbeing? } \\
\text { Does overdiagnosis consist of or sanction the concept of non-harmful } \\
\text { disease? }\end{array}$ \\
\hline Inclusiveness & Does overdiagnosis include medicalization? \\
\hline $\begin{array}{l}\text { Value-ladenness: } \\
\text { which harms and } \\
\text { benefits to include, }\end{array}$ & $\begin{array}{l}\text { Is a person with a correct diagnosis of a disease that cannot be treated } \\
\text { overdiagnosed? }\end{array}$ \\
\cline { 2 - 2 } & Is a person correctly diagnosed with a disease and treated with a \\
\hline
\end{tabular}




\begin{tabular}{ll}
\hline $\begin{array}{l}\text { e.g. treatment } \\
\text { outcomes }\end{array}$ & treatment that has a marginal or no benefit overdiagnosed? \\
\hline Competing mortalities & $\begin{array}{l}\text { Is a person who dies from causes other than an identified disease } \\
\text { overdiagnosed? Can persons with symptoms be overdiagnosed? }\end{array}$ \\
\hline Unity & $\begin{array}{l}\text { Is it possible to define a general or unifying concept of overdiagnosis, or } \\
\text { do we have to rely on specific definitions for specific purposes? }\end{array}$ \\
\hline Metrics & How should overdiagnosis be measured or estimated? \\
\hline Causality & $\begin{array}{l}\text { To what extent does overdiagnosis stem from biological characteristics of } \\
\text { disease, from features of the healthcare system, and/or from a broader } \\
\text { social setting? What are the relationships between its various causes? }\end{array}$ \\
\hline
\end{tabular}

\section{Three perspectives on overdiagnosis}

One reason for the challenge in providing a precise, applicable, and unifying definition of overdiagnosis is that the term refers to complex, multifaceted phenomena that look quite different when analysed from different perspectives. Accordingly, we will investigate three such perspectives: the personal, the professional, and the population perspective. The objective is to increase our understanding of and hence our ability to address overdiagnosis by using these three perspectives to identify what matters and to present a model for their interrelationship. We conclude that these perspectives are irreducible and interdependent and that input from all three is important for understanding and addressing overdiagnosis. Table 2 provides an overview of the three perspectives of overdiagnosis to be investigated.

Table 2 Overview of three perspectives on overdiagnosis: Patient, Professional, Population

\begin{tabular}{|c|c|c|c|}
\hline & Patient & Professional & Population \\
\hline $\begin{array}{l}\text { Underlying } \\
\text { Concepts }\end{array}$ & $\begin{array}{l}\text { ODx as futile or even } \\
\text { harmful diagnosis }\end{array}$ & $\begin{array}{l}\text { ODx as diagnosis of a non- } \\
\text { harmful condition }\end{array}$ & $\begin{array}{l}\text { ODx as diagnoses that do } \\
\text { more harm than good }\end{array}$ \\
\hline $\begin{array}{l}\text { Methods for } \\
\text { obtaining } \\
\text { estimates }\end{array}$ & $\begin{array}{l}\text { Investigating what } \\
\text { matters from a } \\
\text { personal perspective }\end{array}$ & $\begin{array}{l}\text { Professional consensus on } \\
\text { defining disease and } \\
\text { diagnostic criteria } \\
\text { Models of disease } \\
\text { progression } \\
\text { Defining thresholds and cut- } \\
\text { off levels }\end{array}$ & $\begin{array}{l}\text { Excess disease incidence } \\
\text { without gains in } \\
\text { morbidity/mortality } \\
\text { Measuring and balancing } \\
\text { harms and benefits of } \\
\text { diagnosis and subsequent } \\
\text { intervention in populations }\end{array}$ \\
\hline Metrics & $\begin{array}{l}\text { Chance of futile or } \\
\text { even harmful } \\
\text { diagnostics (and } \\
\text { subsequent } \\
\text { treatment) }\end{array}$ & $\begin{array}{l}\text { Degree of biological } \\
\text { abnormality } \\
\text { Dysfunction } \\
\text { Prognostic uncertainty } \\
\text { Cut-off values }\end{array}$ & $\begin{array}{l}\text { Incidence of diagnosis, and } \\
\text { population-based outcomes } \\
\text { (morbidity, mortality), in } \\
\text { defined time periods }\end{array}$ \\
\hline
\end{tabular}




\section{The personal perspective: What do I need to know?}

As a test invitee considering whether or not to undertake a diagnostic (or screening) test, you would among other things like know: (i) whether a positive test is correct; (ii) if it is correct (in finding an indicator or abnormality), whether the finding will ultimately reduce harm (your pain or suffering) from a (potentially) resulting disease diagnosis; and (iii) the consequences of treating the condition based on the test result. You would like to know whether any abnormality identified by the test will progress to anything to worry about, and if so, what can be done to limit those consequences (21). When trying to answer such questions we often look for information, e.g., for predictive values to address question (i). To address question (ii) we need to estimate overdiagnosis, and to do so we must refer to its definition. The traditional working definition describes overdiagnosis as diagnosis of a condition "that would otherwise not go on to cause symptoms or death"(22). As we do not know what would otherwise happen (12), overdiagnosis pertains to prognostic uncertainty (21), making it difficult to provide definitive information to individuals about whether they will experience overdiagnosis of a condition. Likewise, it is difficult to tell an individual whether they personally have or have not been overdiagnosed.

At present, the best we can do is to offer population-based estimates of the probability that individuals like them will experience overdiagnosis. While population-based estimates are more readily used in health policy making $(9,19)$ they are also used in informing individuals, for example through shared decision making tools (23) which make statistical estimates meaningful from the perspective of the individual (24). As expressed by Hirsch and colleagues for breast cancer: The invited person needs to know "the risk of having a cancer diagnosed and treated that would not have presented clinically in her lifetime." (25)

Hence, the patient perspective directs our attention to what matters to the invitee, i.e., (i) how accurately the test result will detect disease; (ii) how likely it is that what is detected will go on to cause pain and suffering (in the absence of treatment); and (iii) whether the treatment that follows on a positive test result will reduce or increase pain or suffering. Answering these questions draws on concepts and knowledge that arise from the professional domain of disease definition and diagnostic thresholds, and information from population level data. We currently lack the technology and knowledge to make accurate predictions at an individual level. 


\section{The professional perspective: which diagnoses are overdiagnoses?}

From a professional perspective, test results or diagnoses are useful to the extent that they identify instances of diseases in ways that can lead to interventions that benefit patients, usually by reducing morbidity and mortality. Overdiagnosis subverts this process by diagnosing instances of apparent disease that will not progress as expected, and which therefore lead to no patient benefits (and often harms) when identified and treated. There is concomitant waste of healthcare resources (10). How a disease is defined determines its extension and affects the numbers of persons being overdiagnosed. Deciding on what counts as disease is not an easy task, as many of the biophysical parameters that can be measured may not predict harmful disease (now or in the future). For instance, cohort studies of persons diagnosed with early stage prostate cancer that were not treated but followed up for 30 years showed that many of them did not develop manifest disease affecting morbidity and/or mortality $(26,27)$. Such findings have challenged the definition of prostate cancer, with implications for management. In some cases, low-risk conditions previously labelled as cancer have been renamed because they are found not to progress to manifest disease and suffering (28, 29).

In addition to defining disease, professionals also specify diagnostic criteria such as which indicators (biomarkers) to use and where to set cut-off levels. These in turn influence the incidence and prevalence of a disease and the overdiagnosis estimates. While lowering diagnostic thresholds for biomarkers may increase the detection rate, it may also increase overdiagnosis.

Hence, both the definition of particular diseases and the accepted diagnostic criteria are relevant in estimates of overdiagnosis, which rely on detection levels, disease progression models, and incidence rates provided by health professionals with help from basic scientists and epidemiologists (14).

One recent definition of disease proposed for reducing overdiagnosis is given by Rogers and Walker who state that " $X$ is a disease $e_{0 x}$ iff there is dysfunction that has a significant probability of causing severe harm." (1). Identifying dysfunction is not a simple issue (30), and needs significant input from health professionals and researchers. Moreover, deciding on what is harmful, how to grade severity of harm, and what counts as a "significant probability" depends on "contextual factors" (1) and rests on input from patients and broader publics. One current challenge is that these normative elements are not explicitly addressed. The definitions and diagnostic criteria rely extensively on professional decision-making. Accordingly, professional definitions and diagnostic criteria must be systematically informed by both epidemiological data and data from comprehensive public consultations in order to be justifiable, legitimate, and informative. 


\section{The population perspective: whose estimates of benefit and harm?}

While there is broad agreement that overdiagnosis can rarely be identified at the level of the individual $(9,19)$, so far there is little concurrence as to how it should be estimated on a population level (by epidemiologists and others). A range of methods for its estimation is available, and there are fierce methodological debates over which method is best and for what purpose (13-16). While population-level estimates are based on data aggregated across individual members of that population, it is only after aggregation and comparison, generally of population-level change over time, that the phenomenon of overdiagnosis can be estimated. Estimating overdiagnosis at a population level, however, inevitably raises questions about which outcomes, variables or data should be included in these estimations, and how these should be measured.

For example, one population-level conception of overdiagnosis focuses on the ways in which tests and diagnoses flow to outcomes, via the cascade of further tests and interventions arising from usual clinical pathways (9). On this view, overdiagnoses are diagnoses that, on balance, do more harm than good. This emphasizes overdiagnosis as a matter for social concern focusing on the link between diagnostic practices and outcomes. Overdiagnosis is occurring when diagnoses that are considered correct in relevant professional communities are, counterintuitively, doing harm instead of providing the expected benefit. This suggests that overdiagnosis is a product of systems: political, policy and professional systems agreeing to decisional defaults that lead to harm instead of benefit.

Hence, the information clinicians provide to individuals is based on estimates from populations based on professional practices and overall conceptions of harms and benefits. Although individual patients may be the origin of the data included in these models through their participation in research or provision of health service data, they are not often consulted as to how the harms and benefits should be conceptualised and counted (9). So, although the population perspective is currently the basis for providing information at the individual level, there may be a mismatch between the information individuals might want or need, and that available from the population perspective.

\section{The interdependence between perspectives: a model}

As long as science cannot predict which individuals will suffer future harm from a disease after having a true positive result from a specific test, and which will not, clinicians and policymakers will have to rely on estimates of overdiagnosis from the population level. In order to make the population level estimates, epidemiologists rely (at least tacitly) on input from the professional perspective on the definition of specific diseases, detection thresholds, and disease progression models. We have argued that these measures should be defined and informed by what matters to 
people, such as harm (pain and/or suffering), and that input on what counts as benefits and harms from patients and professionals is crucial when estimating overall benefits and harms on the population level.

Accordingly, there is strong interdependence between the perspectives. That interdependence, we propose, is rarely acknowledged or made explicit: doing so may assist in resolving some of the conflicts around conceptions of overdiagnosis. Figure 1 shows the relationship between the perspectives and Table 2 provides details for each of the perspectives on overdiagnosis with respect to information content establishment.

Figure 1 A model for the relationship between personal, professional, and population perspectives on overdiagnosis.

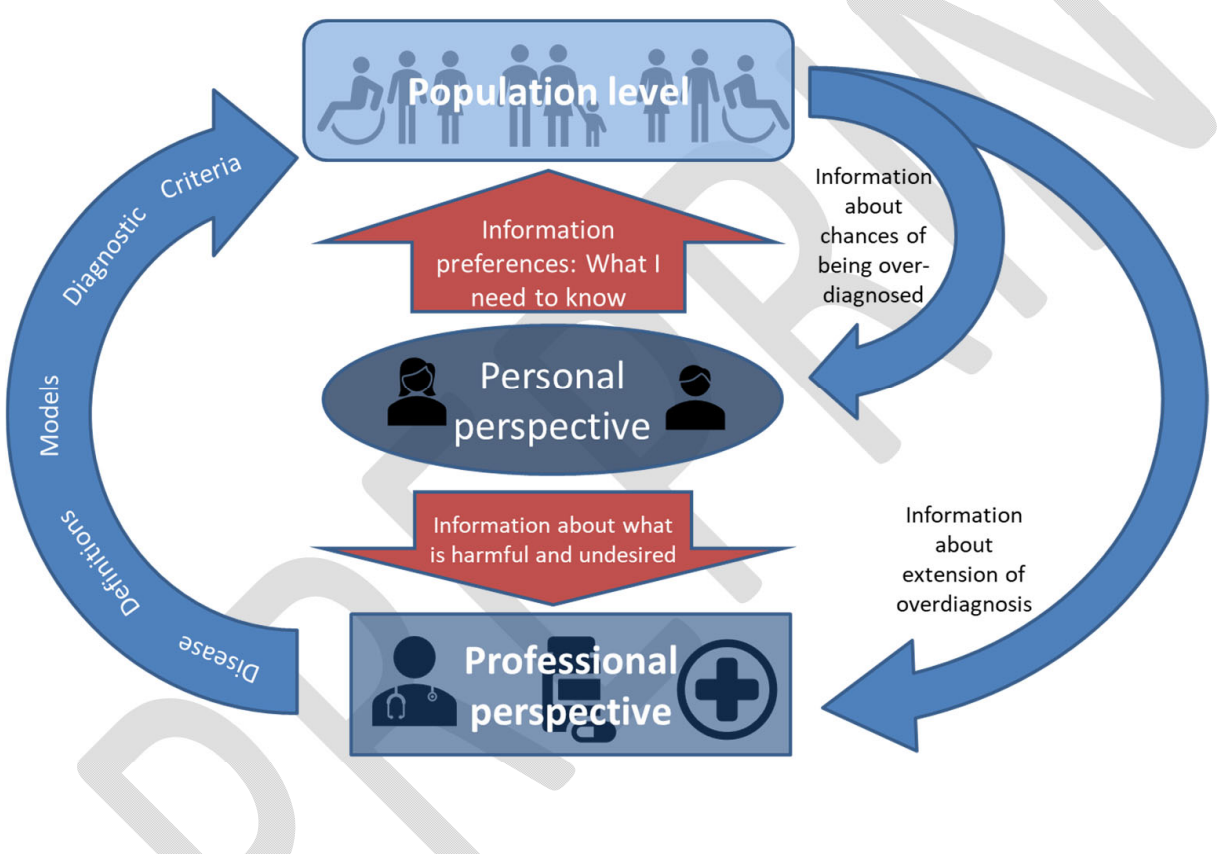

These perspectives are irreducible. The professional perspective cannot be reduced to the personal or population and vice versa as each adds a unique and crucial element to the overall conceptualization of overdiagnosis. Epidemiological conceptions of overdiagnosis, equally, do not adequately capture the personal and professional perspectives on overdiagnosis. Nonetheless, we have illustrated the importance of communication between all perspectives in order to understand and address overdiagnosis. 


\section{Conclusion}

Defining, estimating, communicating, and dealing with overdiagnosis is difficult. While it is to be hoped that improvements in tests and predictive biomarkers will reduce overdiagnosis, such improvements still raise difficult questions about what counts as disease and as overdiagnosis. Innovations in diagnostic testing are also unlikely to eliminate overdiagnosis. We propose therefore that a model distinguishing and relating the different perspectives on overdiagnosis will contribute to progress on addressing it.

We have shown that part of the complexity can be explained by discordance between three perspectives, i.e., that of the person, the professional, and the population. We present this as a schematic mode: in reality, there are more than three stakeholders and there is no unified perspective in a given stakeholder group. Our model is however, aligned to key decision-makers (patients, professionals, and policymakers) and directly relevant to the construction of evidence about the nature and extent of overdiagnosis.

In order to address overdiagnosis in a practical and effective manner, we need to pay attention to all three perspectives and how they interact. Estimates to inform individuals who are offered a test are founded on population-based estimates that depend on professionals' conceptions and models of disease and diagnostic criteria, which in turn depend on individuals' experience of suffering and population level outcomes from diagnostics and treatment. Accordingly, population-based estimates of overdiagnosis must be more directly informed by personal need for information to be justified and legitimate. So must disease definitions and diagnostic criteria. Only then can individuals be appropriately informed about overdiagnosis.

\section{References}

1. Rogers W, Walker M. Précising definitions as a way to combat overdiagnosis. Journal of evaluation in clinical practice. 2018;24(5):1019-25.

2. Walker MJ, Rogers W. Defining disease in the context of overdiagnosis. Medicine, Health Care and Philosophy. 2017;20(2):269-80.

3. Hofmann B. The overdiagnosis of what? On the relationship between the concepts of overdiagnosis, disease, and diagnosis. Medicine, health care, and philosophy. 2017;20(4):453-64. doi:10.1007/s11019-017-9776-z

4. Hofmann B. Overdiagnostic uncertainty. European Journal of Epidemiology. 2017;32(6):5334. doi:10.1007/s10654-017-0260-0

5. van Dijk W, Faber MJ, Tanke MA, Jeurissen PP, Westert GP. Medicalisation and Overdiagnosis: What Society Does to Medicine. International journal of health policy and management. 2016;5(11):619-22. doi:10.15171/ijhpm.2016.121 
6. Hofmann B. Medicalization and overdiagnosis: different but alike. Medicine, health care, and philosophy. 2016;19(2):253-64. doi:10.1007/s11019-016-9693-6

7. Hofmann B. Conceptual overdiagnosis. A comment on Wendy Rogers and Yishai Mintzker's article "Getting clearer on overdiagnosis". Journal of evaluation in clinical practice. 2016.

doi:10.1111/jep.12652

8. Marcus PM, Prorok PC, Miller AB, DeVoto EJ, Kramer BS. Conceptualizing overdiagnosis in cancer screening. Journal of the National Cancer Institute. 2015;107(4):djv014.

9. Carter SM, Degeling C, Doust J, Barratt A. A definition and ethical evaluation of overdiagnosis. Journal of medical ethics. 2016;42:722-4. doi:10.1136/medethics-2015-102928

10. Rogers WA, Mintzker Y. Getting clearer on overdiagnosis. Journal of evaluation in clinical practice. 2016;22(4):580-7. doi:10.1111/jep.12556

11. Rogers WA, Mintzker Y. Response to Brodersen et al's 'Overdiagnosis: what it is and what it isn't'. BMJ evidence-based medicine. 2018;23(3):119-

12. Hofmann B. Diagnosing overdiagnosis: conceptual challenges and suggested solutions. European Journal of Epidemiology. 2014;29(9):599-604. doi:http://dx.doi.org10.1007/s10654-0149920-5

13. de Gelder R, Heijnsdijk EA, van Ravesteyn NT, Fracheboud J, Draisma G, de Koning HJ. Interpreting overdiagnosis estimates in population-based mammography screening. Epidemiologic reviews. 2011;33(1):111-21. doi:10.1093/epirev/mxr009

14. Etzioni R, Gulati R, Mallinger L, Mandelblatt J. Influence of study features and methods on overdiagnosis estimates in breast and prostate cancer screening. Annals of internal medicine. 2013;158(11):831-8.

15. Etzioni R, Gulati R. Recognizing the Limitations of Cancer Overdiagnosis Studies: A First Step Towards Overcoming Them. Journal of the National Cancer Institute. 2016;108(3). doi:10.1093/jnci/djv345

16. Carter JL, Coletti RJ, Harris RP. Quantifying and monitoring overdiagnosis in cancer screening: a systematic review of methods. Bmj. 2015;350:g7773. doi:10.1136/bmj.g7773

17. Carter SM, Doust J, Degeling C, Barratt A. A definition and ethical evaluation of overdiagnosis: response to commentaries. Journal of medical ethics. 2016;42(11):722-4. doi:10.1136/medethics2016-103822

18. Pathirana T, Clark J, Moynihan R. Mapping the drivers of overdiagnosis to potential solutions. BMJ. 2017;358. doi:10.1136/bmj.j3879

19. Davies L, Petitti DB, Martin L, Woo M, Lin JS. Defining, Estimating, and Communicating Overdiagnosis in Cancer Screening. Annals of internal medicine. 2018;169(1):36-43.

20. Brodersen J, Schwartz LM, Heneghan C, O'Sullivan JW, Aronson JK, Woloshin S. Overdiagnosis: what it is and what it isn't. Evidence-based medicine. 2018;23(1):1-3. doi:10.1136/ebmed-2017-110886

21. Hofmann BM. Back to Basics: Overdiagnosis Is About Unwarranted Diagnosis. American Journal of Epidemiology. 2019;188(10):1812-7. doi:http://dx.doi.org10.1093/aje/kwz148

22. Welch HG, Black WC. Overdiagnosis in cancer. Journal of the National Cancer Institute. 2010;102(9):605-13. doi:10.1093/jnci/djq099

23. McCaffery KJ, Jansen J, Scherer LD, et al. Walking the tightrope: communicating overdiagnosis in modern healthcare. BMJ. 2016;352:i348. doi:10.1136/bmj.i348

24. Hofmann B. Getting personal on overdiagnosis: on defining overdiagnosis from the perspective of the individual person. Journal of evaluation in clinical practice. 2018 Accepted.

25. Hersch J, Barratt A, Jansen J, et al. Use of a decision aid including information on overdetection to support informed choice about breast cancer screening: a randomised controlled trial. Lancet. 2015(385):1642-52. doi:10.1016/s0140-6736(15)60123-4

26. Popiolek $\mathrm{M}$, Rider JR, Andrén $\mathrm{O}$, et al. Natural history of early, localized prostate cancer: a final report from three decades of follow-up. European urology. 2013;63(3):428-35.

27. Johansson J-E, Andrén $\mathrm{O}$, Andersson S-O, et al. Natural history of early, localized prostate cancer. JAMA : the journal of the American Medical Association. 2004;291(22):2713-9. 
28. Nickel B, Moynihan R, Barratt A, Brito JP, McCaffery K. Renaming low risk conditions labelled as cancer. BMJ. 2018;362:k3322.

29. Esserman LJ, Thompson IM, Reid B, et al. Addressing overdiagnosis and overtreatment in cancer: a prescription for change. The Lancet. Oncology. 2014;15(6):e234-e42. doi:10.1016/S14702045(13)70598-9

30. Rogers WA, Walker MJ. The Line-drawing Problem in Disease Definition. The Journal of medicine and philosophy. 2017;42(4):405-23. doi:10.1093/jmp/jhx010 